\title{
SPECIAL FEATURES OF THE GRANULAR STRUCTURE OF THE SURFACE ZONE IN PIPE STEEL 12Kh18N12T
}

\author{
E. G. Volkova ${ }^{1}$, V. V. Sagaradze ${ }^{1}$, I. Yu. Malygina ${ }^{2}$ \\ ${ }^{I}$ M.N. Miheev Institute of Metal Physics of Ural Branch of Russian Academy of Sciences, 18 S. Kovalevskoy st., \\ Ekaterinburg, Russian Federation \\ ${ }^{2}$ Institute of Engineering Science, Ural Branch of the Russian Academy of Sciences, 620049, 34 Komsomolskaya st., \\ Ekaterinburg, Russian Federation \\ *Corresponding author. E-mail: volkova@imp.uran.ru; address for correspondence: 18, ul. S. Kovalevskoy, 620990, \\ Ekaterinburg, Russian Federation. Tel.: +7 343 3783527; fax: +7 3433745244
}

The structure of $12 \mathrm{Kh} 18 \mathrm{~N} 12 \mathrm{~T}$ austenitic pipe steel has been studied by scanning and electron microscopy. It has been shown that the lubricant remaining on the internal surface of a pipe after rolling causes an increase in the carbon content in the near-surface layer under subsequent annealings. Carbide particles are formed in the structure near the internal surface, and considerable grain refining is observed.

Keywords: austenitic steels, carbide particles, heterogranularity, electron and scanning microscopy.

DOI: $10.17804 / 2410-9908.2015 .6 .063-067$

\section{References}

1. Gorelik S.S. Rekristallizatsiya metallov i splavov [Recrystallization of Metals and Alloys]. M., Metallurgiya Publ., 1978, 567 p. (In Russian).

2. Gorbachev S.V., Shchipachev A.M., Lutfullin R.Ya. Studying the heterogranularity of steel 20 welded joints under thermomechanical processing. Elektronnyi nauchnyi zhurnal Neftegazovoe delo, 2014, no. 1, pp. 302-316. DOI: 10.17122/ogbus-2014-1-289-301. (In Russian).

3. Nastich S.Yu., Soya S.V., Molostov M.A., Vasiliev I.S., Dyakonova N.B. Effect of temperature for the start of finish rolling on coiled steel X70 microstructure and cold resistance. Metallurgist, 2012, vol. 56, iss. 7-8, pp. 519-525. DOI: 10.1007/s11015-012-9608-6.

4. Goli-Oglu E.A., Efron L.I., Morozov Yu.D. Effect of deformation regime in main stages of controlled rolling on pipe steel microstructure. Metal Science and Heat Treatment, 2013, vol. 55, iss. 5-6, pp. 294-297. DOI: 10.1007/s11041-013-9622-8.

5. Vorobyov Yu.Ya. Thermodynamics, phase composition and structure of steel carbides. I. Carbides of 3D elements. Voprosy materialovedenia, 2007, no. 2, pp. 34-43. (In Russian). 
Подана в журнал: 29.10.2015 г.

УДК 669.14:536.424.1

DOI: $10.17804 / 2410-9908.2015 .6 .063-067$

\title{
ОСОБЕННОСТИ ЗЕРЕННОЙ СТРУКТУРЫ ПОВЕРХНОСТНОЙ ЗОНЫ В ТРУБНОЙ СТАЛИ 12Х18Н12Т
}

\author{
Е. Г. Волкова ${ }^{1 *}$ В. В. Сагарадзе ${ }^{1}$, И. Ю. Малыгина ${ }^{2}$ \\ ${ }^{1}$ Федеральное государственное бюджетное учреждение науки Институт физики металлов имени \\ М.Н. Михеева Уральского отделения Российской академии наук, 620990, ул. С.Ковалевской, 18, \\ Екатеринбург, Российская Федеращия \\ ${ }^{2}$ Федеральное государственное бюджетное учреждение науки Институт машиноведения \\ Уральского отделения Российской академии наук, 620049, ул. Комсомольская, 34, \\ Екатеринбург, Российская Федераџия
}

*Ответственный автор. Электронная почта: volkova@imp.uran.ru; адрес для переписки: ул. С. Ковалевской, 18, 620990, Екатеринбург, Российская Федерация. Телефон: +7 (343) 374-40-54; факс: +7 (343) 374-52-44

Методами сканирующей и просвечивающей микроскопии исследована структура аустенитной трубной стали 12 Х18Н12Т. Показано, что смазка, оставшаяся на внутренней поверхности трубы после прокатки, при последующих отжигах приводит к увеличению содержания углерода в приповерхностном слое. В структуре вблизи внутренней поверхности формируются карбидные частицы и наблюдается существенное измельчение зерна.

Ключевые слова: аустенитные стали, карбидные частицы, разнозернистость, электронная и сканирующая микроскопия.

\section{1. Введение}

В настоящее время на предприятиях, выпускающих трубную продукцию, часто остается нерешенной проблема создания труб с одинаковыми по размерам зернами. Известно [1-4], что размер зерна в значительной степени влияет на физико-химические свойства металлов и сплавов. Разнозернистость весьма разнообразна по своим проявлениям и может отрицательно воздействовать на механические свойства. Обычно наблюдается измельчение зерна вблизи внутренней поверхности трубы. Настоящая работа посвящена анализу причин появления поверхностной разнозернистости в трубной стали $12 \mathrm{X} 18 \mathrm{H} 12 \mathrm{~T}$.

\section{2. Материал и методика исследования}

Сталь 12Х18Н12Т является коррозионно-стойкой и выпускается, в основном, в виде прутков, листа и труб. В работе исследуется труба с толщиной стенки 6 мм из стали $12 \mathrm{X} 18 \mathrm{H} 12 \mathrm{~T}$. Методами сканирующей и просвечивающей электронной микроскопии на установках Quanta 200 и JEM 200CX соответственно была изучена микроструктура стали вблизи внешней и внутренней поверхностей трубы. Фольги для электронно-микроскопического исследования были вырезаны из внешнего и внутреннего участков трубы. Утонение проводили стандартным методом электрополировки в электролите $\mathrm{H}_{3} \mathrm{PO}_{4}+\mathrm{CrO}_{3}$. В работе выполнен микроанализ состава стали 12X18Н12T на сканирующем микроскопе Quanta 200 и спектрометре SPECTROMAX.

\section{3. Экспериментальные результаты и их обсуждение}

На рис. 1 представлена зеренная структура внутреннего участка трубы, выявленная на продольном срезе. Наблюдаемые полиэдрические зерна аустенита характерны для рекристаллизованной стали 12 X18Н12T, закаленной от высокой температуры. Размер зерна в поверхностном слое толщиной около 150 мкм существенно меньше, чем в остальном объеме 


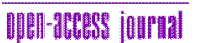

материала. Во внутреннем поверхностном слое трубы мелкое зерно составляет 2-17 мкм, что почти на порядок меньше, чем зерно в середине стенки трубы, где оно достигает величины 50-80 мкм.

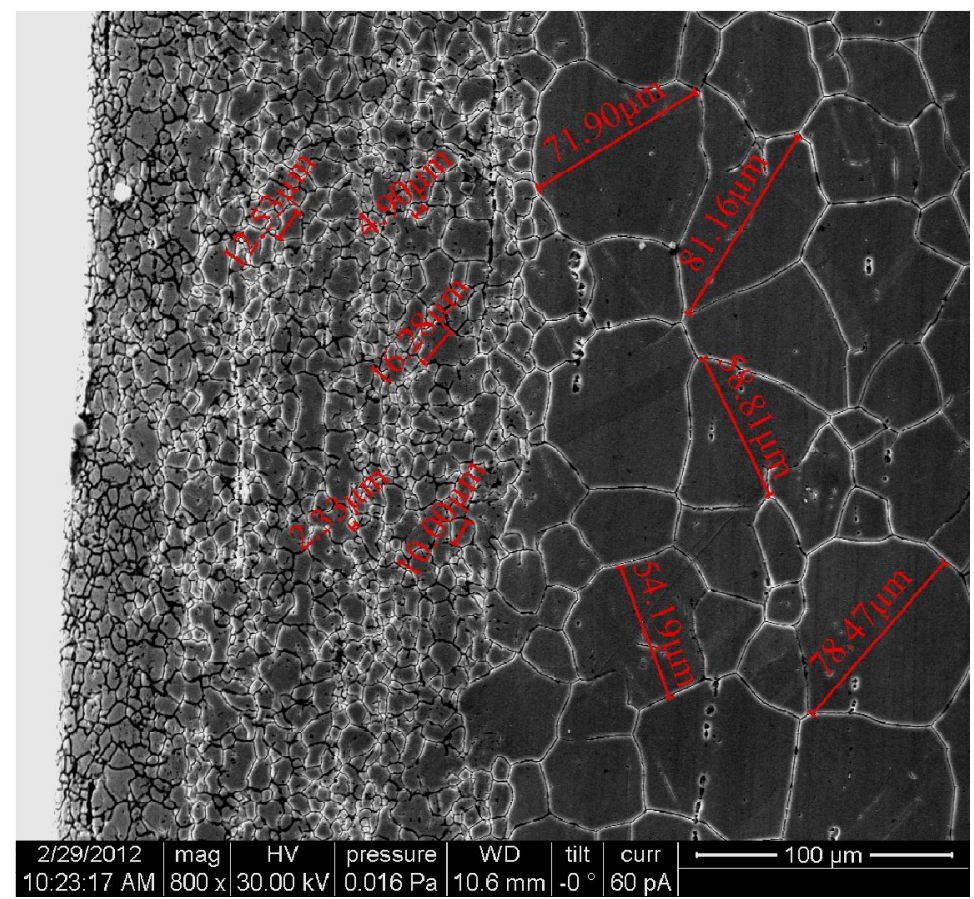

Рис. 1. Зеренная структура внутреннего участка трубы из стали $12 \mathrm{X} 18 \mathrm{H} 12 \mathrm{~T}$

На поверхности образца (рис. 2) встречаются ограненные частицы размером 3-4 мкм и меньше, по внешнему виду похожие на карбид ТiC [5]. Данные по микроанализу состава этих частиц также свидетельствуют об образовании карбида ТіС с повышенном содержанием титана (сведения по содержанию углероду сильно разнятся и это связано с методическими особенностями сканирующей микроскопии, которая дает большую ошибку в определении количества легких элементов). Кроме этого, в образце наблюдаются строчечные выделения более мелких углеродсодержащих частиц с увеличенной концентрацией Ті и в некоторых случаях - Cr.

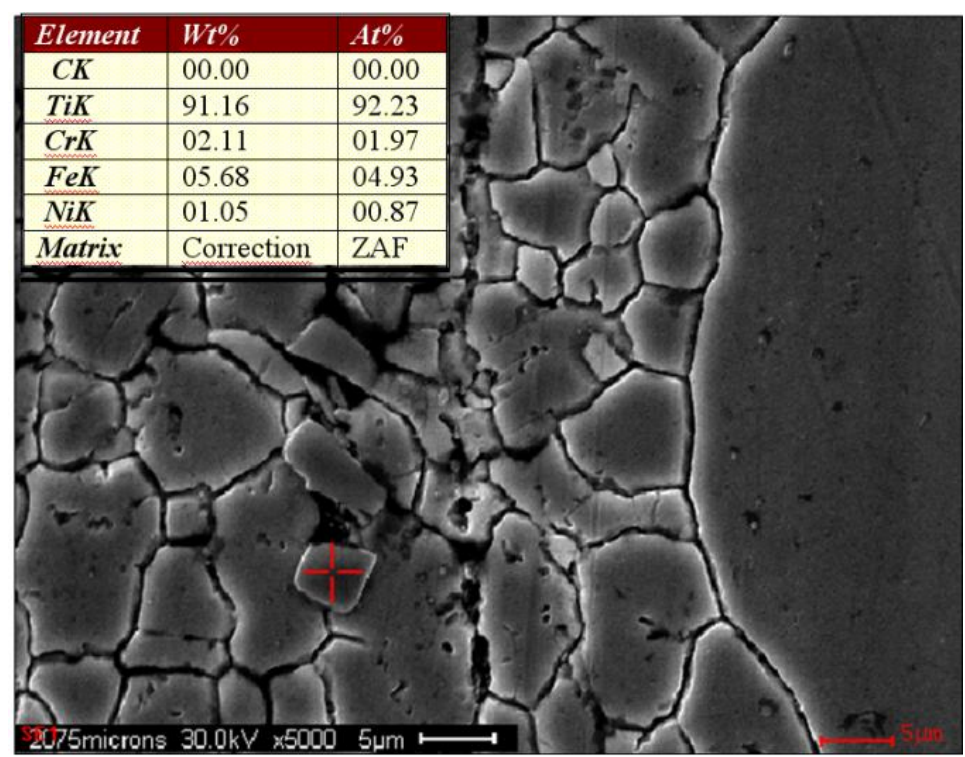

Рис. 2. Структура поверхностной зоны и состав ограненных частиц типа ТiС в трубе из стали 12Х18Н12Т (крестиком отмечена частица, с которой проводился микроанализ) 
Электронно-микроскопическое исследование тонкой структуры образцов проводили на фольгах, вырезанных как из внутренней приповерхностной зоны трубы, так и из ее средней части. На рис. 3 а показана структура образца, вырезанного из средней части трубы. Хорошо видны крупные зерна, а также двойники отжига. Достаточно редко встречаются крупные частицы карбида титана, характерные для легированной титаном нержавеющей стали. На рис. 3 б показана структура образца, вырезанного из участка вблизи к внутренней поверхности трубы. В отличие от предыдущего образца во всех зернах присутствует существенно большое количество карбидных частиц типа ТіС. Возможно здесь же располагаются и карбиды хрома. Карбидные частицы имеют размеры до 100 нм и когерентно не связаны с матрицей. Частицы расположены как в объеме зерен, так и по их границам. Такие частицы должны сдерживать миграцию границ зерен, что приводит к сохранению мелкозернистого состояния при высоких температурах. Поэтому в этой поверхностной зоне трубы (в области интенсивного выделения карбидов) наблюдается более мелкое зерно, чем в участках, удаленных от внутренней поверхности трубы и содержащих существенно меньшее количество карбидов.

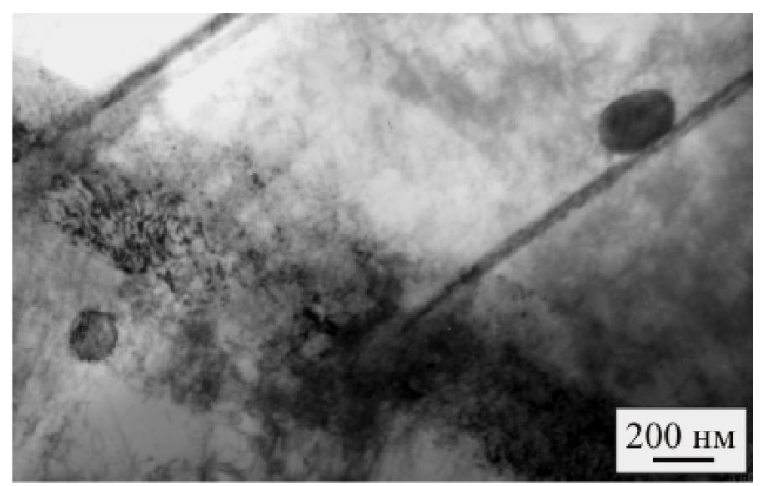

$a$

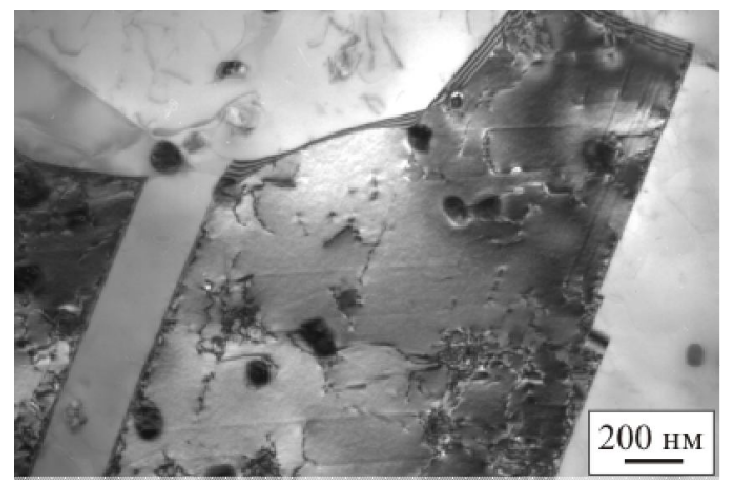

$\sigma$

Рис. 3. Структура образцов стали 12 Х18Н12Т, вырезанных крупнозернистой средней части стенки трубы $(a)$ и из мелкозернистой внутренней поверхностной зоны трубы (б)

Для определения разницы в содержании углерода вблизи внутренней и внешней поверхности трубы были проведены исследования на спектрометре Spektromax, данные которого по углероду намного точнее, чем результаты, получаемые на сканирующем микроскопе Quanta 200. В таблице представлены результаты анализа состава по 22 элементам как с внутренней поверхности трубы (1-3 строки), так и с ее внешней поверхности (4-5 строки). Хорошо видно, что содержание углерода $(0,12-0,14$ мас. \%) по крайней мере в 1,5 раза выше во внутреннем мелкозернистом участке трубы (по сравнению с крупнозернистым внешним участком $(0,8-0,9$ мас. \%), который не контактировал с углеродсодержащей смазкой при изготовлении трубы. По остальным элементам значения меняются незначительно.

Таким образом, причиной значительной разнозернистости стали $12 \mathrm{X} 18 \mathrm{H} 12 \mathrm{~T}$ вблизи внутренней и наружной поверхностей трубы, является дополнительное легирование углеродом внутренней зоны трубы (из углеродсодержащей смазки) в условиях высокотемпературной обработки трубной заготовки. Легирование углеродом внутренней поверхностной зоны трубы вызывает образование дополнительного количества карбидов титана (и возможно карбидов хрома), которые сдерживают миграцию границ зерен при высокотемпературной обработке и способствуют сохранению мелкокристаллической структуры. 
Данные спектрального анализа по элементам (спектрометр Spektromax), мaс. \%

\begin{tabular}{|c|c|c|c|c|c|c|c|c|c|c|c|}
\hline № & $\mathrm{C}, \%$ & $\mathrm{Si}, \%$ & Mn, \% & $\mathbf{P}, \%$ & $\mathrm{~S}, \%$ & $\mathrm{Cr}, \%$ & $\mathrm{Ni}, \%$ & Мо, \% & Al, \% & $\mathrm{Cu}, \%$ & Co, \% \\
\hline 1 & 0,094 & 0,59 & 1,31 & 0,047 & 0,022 & 17,75 & 10,57 & 0,211 & 0,049 & 0,230 & 0,057 \\
\hline 2 & 0,080 & 0,58 & 1,28 & 0,046 & 0,018 & 17,49 & 10,63 & 0,212 & 0,048 & 0,235 & 0,055 \\
\hline 3 & 0,079 & 0,58 & 1,29 & 0,046 & 0,019 & 17,63 & 10,62 & 0,212 & 0,048 & 0,231 & 0,050 \\
\hline 4 & 0,124 & 0,59 & 1,29 & 0,054 & 0,021 & 17,54 & 10,62 & 0,211 & 0,051 & 0,239 & 0,056 \\
\hline 5 & 0,141 & 0,59 & 1,28 & 0,055 & 0,022 & 17,35 & 10,78 & 0,212 & 0,050 & 0,236 & 0,057 \\
\hline № & Ti, \% & $\mathrm{Nb}, \%$ & $V, \%$ & $\mathrm{~W}, \%$ & $\mathrm{~Pb}, \%$ & B, \% & Sn, \% & As, $\%$ & Bi, \% & $\mathrm{Ca}, \%$ & Fe, \% \\
\hline 1 & 0,418 & 0,016 & 0,058 & 0,070 & 0,0063 & 0,0021 & 0,012 & 0,025 & $<0,0020$ & 0,0011 & 68,5 \\
\hline 2 & 0,420 & 0,017 & 0,056 & 0,077 & 0,0073 & 0,0021 & 0,010 & 0,020 & $<0,0020$ & 0,0007 & 68,7 \\
\hline 3 & 0,434 & 0,016 & 0,057 & 0,070 & 0,0054 & 0,0021 & 0,0091 & 0,019 & $<0,0020$ & 0,0008 & 68,6 \\
\hline 4 & 0,429 & 0,015 & 0,057 & 0,071 & 0,0054 & 0,0022 & 0,0091 & 0,024 & $<0,0020$ & 0,0020 & 68,6 \\
\hline 5 & 0,440 & 0,015 & 0,056 & 0,066 & 0,0045 & 0,0022 & 0,011 & 0,023 & $<0,0020$ & 0,0021 & 68,6 \\
\hline
\end{tabular}

Примечание. № 1-3 получены с внешней стороны трубы; № 4, 5 - с внутренней стороны трубы.

\section{Заключение}

Показано, что содержание углерода во внутреннем слое (толщиной около 150 мкм) трубы из стали $12 \mathrm{X} 18 \mathrm{H} 12 \mathrm{~T} \sim 1,5$ раза превышает концентрацию углерода в остальной части трубы, что связано с технологией изготовления труб с использованием углеродсодержащей смазки. Такое увеличение углеродной компоненты приводит к появлению значительного количества карбидов ТіС (и возможно карбидов хрома) во внутреннем поверхностном слое, что сдерживает рост зерна и сохраняет в этой зоне мелкое зерно размером 2-17 мкм.

\section{Благодарность}

Электронно-микроскопические исследования проведены в ОЭМ ЦКП ИФМ УрО РАН. Работа выполнена в рамках государственного задания ФАНО России (тема «Структура», № 01201463331) и при частичной поддержке Уральского отделения РАН (проект № 15-9-2-16).

Авторы благодарны за помощь в работе И. Ю. Пышминцеву, Б. В. Баричко, А. А. Бакуновой (открытое акционерное общество «РосНИТИ).

\section{Литература}

1. Горелик С. С. Рекристаллизация металлов и сплавов. - М. : Металлургия, 1978. -567 с.

2. Горбачев С. В., Щипачев А. М., Лутфуллин Р. Я. Исследование разнозернистости при деформационно-термической обработке сварных соединений из стали 20 // Электронный научный журнал «Нефтегазовое дело». - 2014. - № 1. - С. 302-316.

3. Nastich S. Yu., Soya S. V., Molostov M. A., Vasiliev I. S., Dyakonova N. B. Effect of temperature for the start of finish rolling on coiled steel X70 microstructure and cold resistance // Metallurgist. - 2012. - Vol. 56, iss. 7-8. - P. 519-525. - DOI: 10.1007/s11015-012-9608-6.

4. Goli-Oglu E. A., Efron L. I., Morozov Yu. D. Effect of deformation regime in main stages of controlled rolling on pipe steel microstructure // Metal Science and Heat Treatment. - 2013. Vol. 55, iss. 5-6. - P. 294-297. - DOI: 10.1007/s11041-013-9622-8.

5. Воробьев Ю. Я. Термодинамика, фазовый состав и структура карбидов стали. І. Карбиды 3D-элементов // Вопросы материаловедения. - 2007. - № 2. - С. 34-43. 